\title{
Post-transplant withdrawal of lamivudine results in fatal hepatitis flares in kidney transplant recipients, under immune suppression, with inactive hepatitis B infection
}

\author{
Bin $\mathrm{Miao}^{1}$, Xiang-Ming $\mathrm{Lao}^{2}$, Guo-Li Lin ${ }^{3}$
}

1. Department of Organ Transplantation, The Third Affiliated Hospital of Sun Yat-sen University, Guangzhou, China.

2. Department of Hepatobilliary Disorders, Cancer Center Sun Yat-sen University, Guangzhou, China.

3. Department of Infectious Diseases, The Third Affiliated Hospital of Sun Yat-sen University, Guangzhou, China.

\begin{abstract}
Objective: To evaluate the consequences of lamivudine withdrawal in kidney transplant recipients, under immunosuppression, with inactive hepatitis B virus (HBV) infection.

Introduction: HBV infection is more frequent in kidney transplant recipients than in the general population mainly due to the high risk of acquisition during dialysis, before kidney transplantation.

Methods: The records of hepatitis B surface antigen ( $\mathrm{HBsAg}$ )-positive, immunosuppressed kidney transplant recipients, where lamivudine was withdrawn after transplantation along with reduction in immunosuppressant dose, admitted to our hospital between 2005 and 2012, were retrospectively evaluated.

Discussion: Three patients aged 33, 42 and 33, experienced hepatitis flares 2-3 months after lamivudine withdrawal. Serum HBV DNA levels were $2.5 \times 10^{7}, 3.4 \times 10^{4}$ and $4 \times 10^{3} \mathrm{IU} / \mathrm{ml}$ in cases 1,2 , and 3 , respectively. Lamivudine was re-initiated in all cases which led to rapid viral suppression. However, liver function continued to deteriorate leading to severe jaundice, coagulopathy and encephalopathy. All patients died of acute liver failure within six months after the onset of withdrawal hepatitis.

Conclusion: Lamivudine should be continued as long as immunosuppressive therapy lasts.

Keywords: Hepatitis B virus, lamivudine, kidney transplantation

DOI: http://dx.doi.org/10.4314/ahs.v16i4.27

Cite as: Miao B, Lao X-M, Lin G-L. Post-transplant withdrawal of lamivudine results in fatal hepatitis flares in kidney transplant recipients, under immune suppression, with inactive hepatitis B infection. Afri Health Sci. 2016;16(4): 1094-1100. http:/ / dx.doi.org/10.4314/abs.v16i4.27
\end{abstract}

\section{Introduction}

Hepatitis B virus (HBV) is a major global public health problem. There are more than 350 million chronic HBsAg carriers Worldwide, 75\% of whom reside in the Asia Pacific region ${ }^{1}$. Though HBsAg carrier rate, in China, has decreased from $9.8 \%$ in 1992 to $7.2 \%$ in 2006 following the universal application of hepatitis $B$ vaccination ${ }^{2}$, it is estimated that 100 million people in China are still HBsAg-positive. HBV infection is more frequent in kidney
Corresponding author:
Bin Miao,
Department of Organ Transplantation,
The Third Affiliated Hospital of Sun
Yat-sen University,
600 Tianhe road, Tianhe District,
Guangzhou 510630, China.
Tel.: +86 13609038225; fax: +86 02082179517;
E-mail: 2672964078@qq.com

transplant recipients than in the general population mainly due to the high risk of acquisition during dialysis, before kidney transplantation ${ }^{3}$. A survey conducted in 2003 suggests that the HBsAg carrier rate in 11 Asian-Pacific countries ranged from 2 to $10 \%$ in patients on peritoneal dialysis, 2 to $20 \%$ in patients on hemodialysis, and 1 to $25 \%$ in kidney transplant recipients ${ }^{4}$. The etiological factor, kidney transplantation, is further complicated by the use of immunosuppressants which may consequently enhance HBV replication ${ }^{3}$. Therefore, HBVinfection in kidney recipients is associated with a higher rate of liver-related morbidity and mortality ${ }^{5}$.

Antiviral treatment with nucleos(t)ide analogues (NAs) that inhibit viral reverse transcriptase is recommended and has been shown to improve the prognosis of HBV infection in kidney recipients ${ }^{6,7}$. Lamivudine was the first FDA-approved NA and in spite of a high rate of drug resistance, it is still widely used in $\mathrm{HBsAg-positive} \mathrm{kid-}$ ney recipients ${ }^{8}$. However, the optimal duration of antiviral treatment is controversial ${ }^{9}$. Data on $\mathrm{HBV}$ reactivation 
induced by lamivudine withdrawal in immunocompromised patients are scarce. The aim of this study was to evaluate the consequences of lamivudine withdrawal in kidney transplant recipients, under immunosuppression, with inactive $\mathrm{HBV}$ infection.

\section{Patients and methods}

We retrospectively evaluated the records of immunosuppressed kidney transplant recipients, admitted to the Department of Organ Transplantation and the Department of Infectious Diseases in our hospital between 2005 and 2012, who were also hepatitis B surface antigen (HBsAg)-positive and where lamivudine was withdrawn after transplantation, along with the reduction in immunosuppressant dose.

Three patients were identified who met the above criteria, who were all male patients. They were all diagnosed of chronic glomerulonephritis leading to end-stage renal disease for which they were initially subjected to hemodialysis, later performed primary kidney transplantation from $\mathrm{ABO}$ blood type compatible cadaveric donors.

Prior to kidney transplantation, all patients were seropositive for $\mathrm{HBsAg}$, hepatitis $\mathrm{B}$ core antibody $(\mathrm{HBcAb})$ and hepatitis B early antibody ( $\mathrm{HBeAb})$ for at least 6 months, and were seronegative for hepatitis B surface antibody (HBsAb) and hepatitis B envelope antigen (HBeAg). Serum HBV DNA of all patients was undetectable. Hepatitis $C$, hepatitis $D$, and human immunodeficiency virus infected subjects were not considered for the study. Alcohol consumption did not exceed $20 \mathrm{~g}$ daily. Liver function tests including alanine aminotransferase (ALT),total bilirubin (TB), international normalized ratio (INR), and albumin remained generally normal and stable for more than one year. All the patients were Child-Pugh score A, and had normal ultrasound liver imaging. The clinical data of these patients is listed in Table 1. One month after kidney transplantation, serum creatinine decreased to the normal range in all three patients.

Serum HBsAg, HBsAb, $\mathrm{HBeAg}, \mathrm{HBeAb}$ and $\mathrm{HBcAb}$ were assayed by the Abbott AxSYM Automated Immunoassay Analyzer (Abbott Diagnostics, Illinois, USA). HBV DNA was quantified using the GeneAmp 5700 Sequence Detection System (Applied Biosystems Inc., California, USA). The lower limit of detection was $200 \mathrm{IU} /$ $\mathrm{ml}$. The upper normal limit for ALT was $35 \mathrm{IU} / \mathrm{L}$, and for TB was $1.4 \mathrm{mg} / \mathrm{dl}$. The normal range of albumin was 3.6 to $5.1 \mathrm{~g} / \mathrm{dl}$.

Initial intravenous pulses of methylprednisolone at doses of $0.5-1.0 \mathrm{~g}$ were administered within 1 hour before reperfusion, and the subsequent doses of $0.5 \mathrm{~g} / \mathrm{d}$ were spread over 3 days, followed by prednisone at a dose of $30 \mathrm{mg} / \mathrm{d}$. The prednisone dose gradually reduced to 15 $\mathrm{mg} / \mathrm{d}$ within 30 days, and then $10 \mathrm{mg} / \mathrm{d}$ after 90 days. Mycophenolate mofetil dose was $2 \mathrm{~g} / \mathrm{d}$ on days 0 to 15 , $1.5 \mathrm{~g} / \mathrm{d}$ on days 16 to 30 , and $1 \mathrm{~g} / \mathrm{d}$ after 30 days. The daily cyclosporine dose was $5-8 \mathrm{mg} / \mathrm{kg}$ orally given twice for the first three months, and then $3-5 \mathrm{mg} / \mathrm{kg}$ in the maintenance phase. The cyclosporine dose was adjusted to maintain target whole-blood trough levels of 200-250 $\mathrm{ng} / \mathrm{ml}$ within 90 days, and 100-200 $\mathrm{ng} / \mathrm{ml}$ after 90 days. Induction therapy with intravenous rabbit anti-thymocyte globulin $(0.5-1.5 \mathrm{mg} / \mathrm{kg} / \mathrm{d}$ from days 0 to 5 , corresponding to a cumulative dose of $2.5-5 \mathrm{mg} / \mathrm{kg}$ ) was used in all patients. An acute rejection episode in case 3 that occurred 4 years after transplantation was treated with methylprednisolone at a cumulative dose of $2 \mathrm{~g}$, and porcine anti-lymphocyte globulin at a cumulative dose of $750 \mathrm{mg}$.

Lamivudine was initially prescribed as prophylaxis against HBV reactivation at a dose of $100 \mathrm{mg} / \mathrm{d}$, and later adjusted according to the creatinine level. Lamivudine was started at the time of kidney transplantation, and was continued for 3 months and 4 years in cases 1 and 3, respectively. In case 3 , lamivudine was withdrawn just 1 month after treatment for acute rejection. Case 2 was treated with lamivudine for 5 weeks before kidney transplantation, and stopped immediately after kidney transplantation.

The levels of serum ALT, TB creatinine and INR were measured two to three times per week for 1 month, weekly for months 2 and 3 and every 2-4 weeks for months 4-6. HBV DNA was evaluated after 1 month of lamivudine treatment, and was undetectable in cases 1 and 2. HBV DNA was undetectable during lamivudine treatment in case 3, who had HBV DNA checked every 6 months. Serum HBsAg, HBsAb, HBeAg, HBeAb, HB$c A b, H B V-D N A$ and INR were measured at the time of onset of hepatitis flares. 
A hepatitis flare was defined as a rise in serum ALT level to greater than 2 -fold of the upper normal limit. Acute liver failure was defined as the onset of coagulopathy (INR $\geq 1.5)$ and any degree of hepatic encephalopathy within 26 weeks of the appearance of symptoms ${ }^{10}$.

\section{Results}

A total of 278 end stage renal disease patients received kidney transplantation between 2005 and 2012 at the Department of Organ Transplantation and the Department of Infectious Diseases, in our hospital. Of these a total of 35 patients were found to be HBsAg positive and all of them received post-transplant lamivudine therapy. Four of these patients showed signs of hepatitis flare and were considered as lamivudine non-responders and were successfully treated with another nucleos(t)ide analogue. No other patients demonstrated hepatitis flare except for 3 patients in whom lamivudine was withdrawn on the decision of the attending physician. These patients presented to the outpatient department, two to three months $(68,85$ and 80 days in case 1,2 and 3 respectively) after lamivudine withdrawal, with anorexia and malaise since 1-2 weeks, and were admitted to the hospital. On admission, physical examination revealed that they were well-oriented and alert but slightly icteric. The livers were not palpable. Temperature, blood pressure, pulse rate and respiratory rate remained within the normal range. ALT levels were 122, 53 and $273 \mathrm{IU} / \mathrm{L}$, TB levels were 17.2, 6.6 and $29.1 \mathrm{mg} / \mathrm{dl}$, and Serum HBV DNA levels were $2.5 \times 10^{7}, 3.4 \times 10^{4}$ and $4 \times 10^{3} \mathrm{IU} / \mathrm{ml}$, prothrombin times were INR 1.3, 1.57, 1.52 in cases 1,2 , and 3, respectively, and thus were diagnosed as hepatitis flare. Sero-reversion from $\mathrm{HBeAb}$ to $\mathrm{HBeAg}$ occurred in cases 2 and 3. No co-infection with other viruses including hepatitis A, hepatitis $\mathrm{C}$, hepatitis D, cytomegalovirus and human immunodeficiency virus were identified.

Lamivudine was re-initiated on the first hospital day except in case 3 where it had been started 2 weeks before admission. One week after admission, serum HBV DNA decreased to $1 \times 10^{7} \mathrm{IU} / \mathrm{ml}$ in case 1 , and was undetectable in cases 2 and 3. Cyclosporine was switched to tacrolimus at a dose of $1 \mathrm{mg} / \mathrm{d}$ in case 1 , and stopped in cases 2 and 3. Mycophenolate mofetil dose was reduced to $0.5 \mathrm{~g} / \mathrm{d}$ in all patients. The prednisone doses were 15, 20, and 10 $\mathrm{mg} / \mathrm{d}$ in cases 1, 2 and 3, respectively. Despite supportive treatment and minimization of immunosuppressive dose, the clinical condition of all three patients continued to deteriorate as evidenced by severe jaundice, coagulopathy and encephalopathy. Laboratory test results for these patients are shown in Table 2 . ALT levels peaked on day 0 in case $1(122 \mathrm{IU} / \mathrm{L})$ and $3(273 \mathrm{IU} / \mathrm{L})$ and on day 12 in case 2 (253IU/L) (Figure 1).

Table 1: Pre-transplantation clinical characteristics in HBsAg-positive kidney transplant recipients

\begin{tabular}{llll}
\hline Characteristics & Case 1 & Case 2 & Case 3 \\
\hline Age(years) & 33 & 42 & 33 \\
Gender & Male & Male & Male \\
HBV DNA (IU/ml) & Undetectable & Undetectable & Undetectable \\
ALT (IU/L) & 43 & 26 & 56 \\
TB (mg/dl) & 0.3 & 0.4 & 0.5 \\
INR & 0.92 & 1.01 & 1.02 \\
Albumin (g/dl) & 3.9 & 3.8 & 3.4 \\
Child-Pugh score & 5 & 5 & 5 \\
\hline
\end{tabular}


Table 2. Serum biochemistry (ALT, TB, INR and creatinine) during hospitalization

\begin{tabular}{ccccccccccccc}
\hline \multirow{2}{*}{ Day } & \multicolumn{3}{c}{ ALT(IU/L) } & \multicolumn{3}{c}{ TB(mg/dl) } & \multicolumn{3}{c}{ INR } & \multicolumn{3}{c}{ Creatinine(mg/dl) } \\
\cline { 2 - 13 } & case1 & case2 & case3 & case1 & case2 & case3 & case1 & case2 & case3 & case1 & case2 & case3 \\
\hline 0 & 122 & 53 & 273 & 17.2 & 6.6 & 29.1 & 1.3 & 1.57 & 1.52 & 1.3 & 1.4 & 1.7 \\
3 & 101 & 75 & 209 & 19.6 & 9.6 & 27.7 & & & & 1.4 & 1.1 & 1.8 \\
6 & 80 & 321 & 89 & 24.3 & 14.6 & 28.1 & 1.94 & 1.95 & 1.81 & 2.3 & 1 & 1.6 \\
12 & 76 & 253 & 33 & 39.6 & 28.7 & 33.2 & 5.16 & 4.24 & 1.91 & 6.3 & 4.1 & 1.4 \\
30 & & & 42 & & & 38.3 & & & 2.18 & & & 1.2 \\
60 & & & 85 & & & 30.2 & & & 3.84 & & & 2.1 \\
90 & & & 71 & & & 19 & & & 3.71 & & & 1.3 \\
\hline
\end{tabular}

TB levels peaked on day 12 in case $1(39.6 \mathrm{mg} / \mathrm{dl})$ and 2 (28.7mg/dl), and on day 30 in case $3(38.3 \mathrm{mg} / \mathrm{dl})$

(Figure 2).

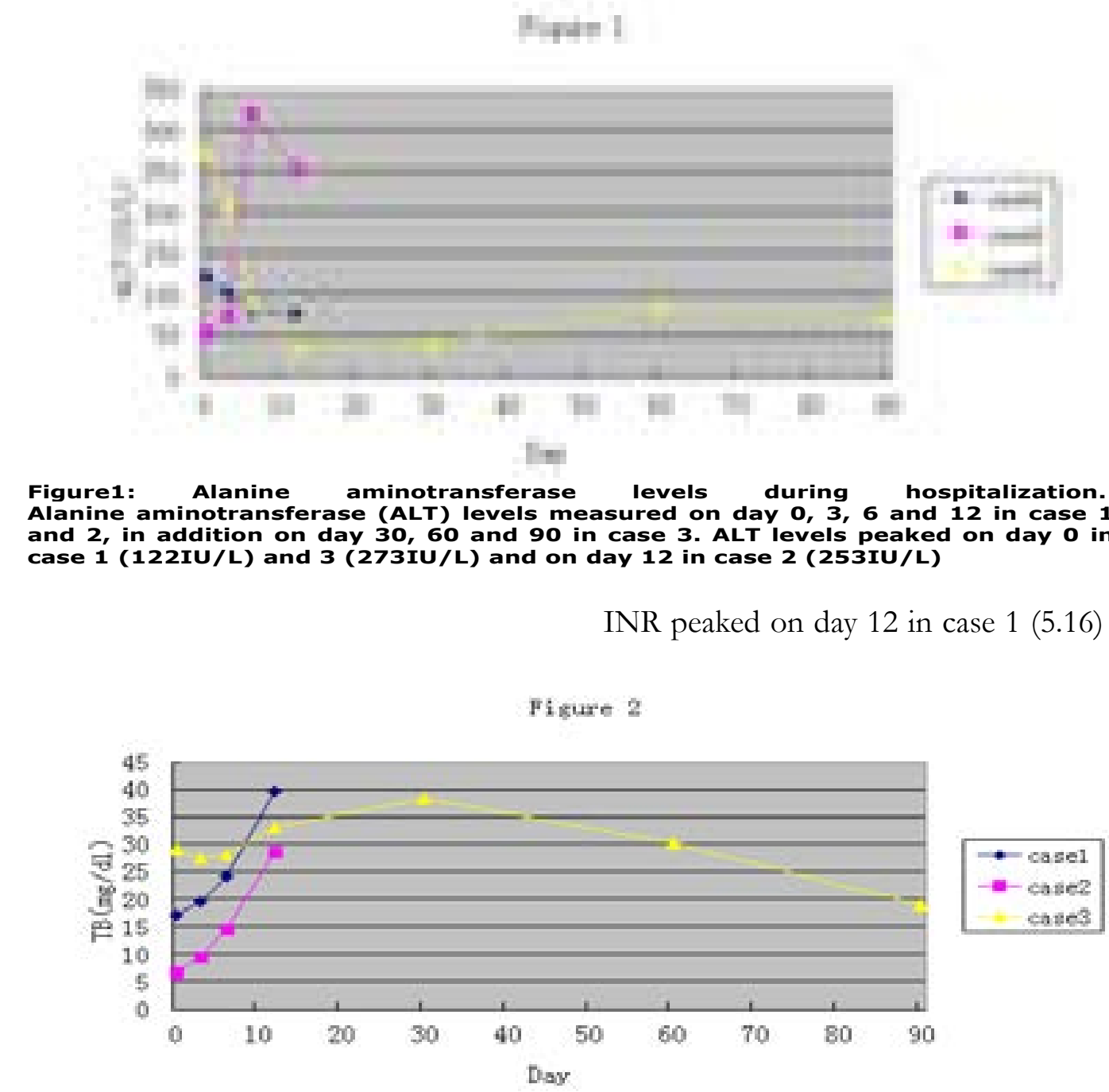

Figure 2: Total bilirubin levels during hospitalization.

Total bilirubin (TB) levels peaked on day 12 in case $1(39.6 \mathrm{mg} / \mathrm{dl})$ and $2(28.7 \mathrm{mg} / \mathrm{dl})$, and on day 30 in case $3(38.3 \mathrm{mg} / \mathrm{dl})$. 
and on day 60 in case 3 (3.84) (Figure 3).

The serum creatinine levels peaked on day 12 for case 1 (2.1) (Figure 4).

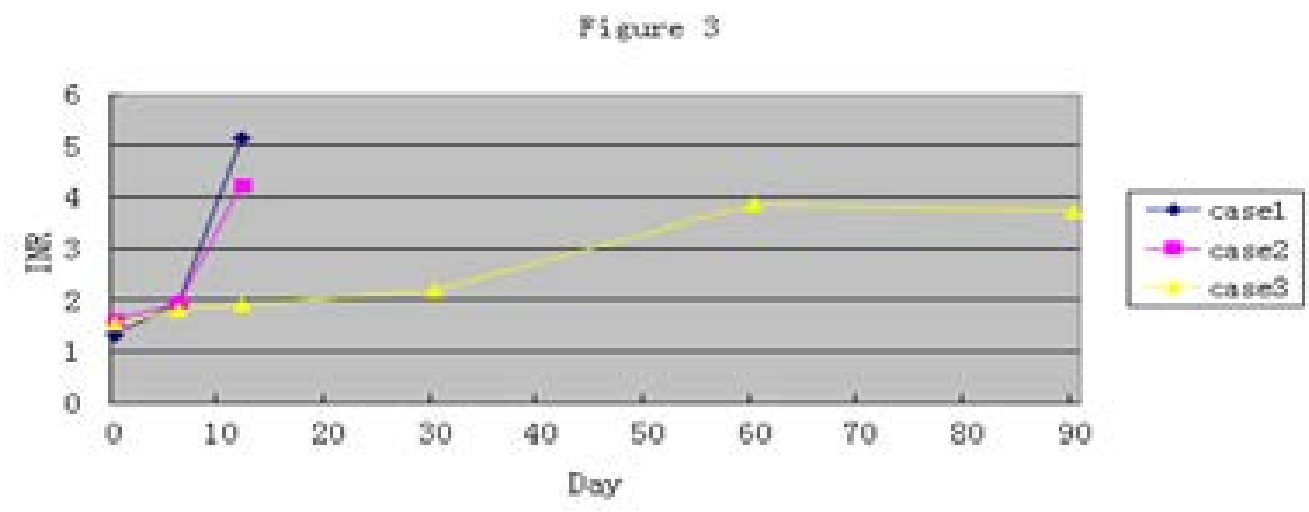

Figure 3: International normalized ratio levels during hospitalization. International normalized ratio (INR) levels peaked on day 12 in case 1 (5.16) and case $2(4.24)$, and on day 60 in case $3(3.84)$.

\section{Fisure 4}

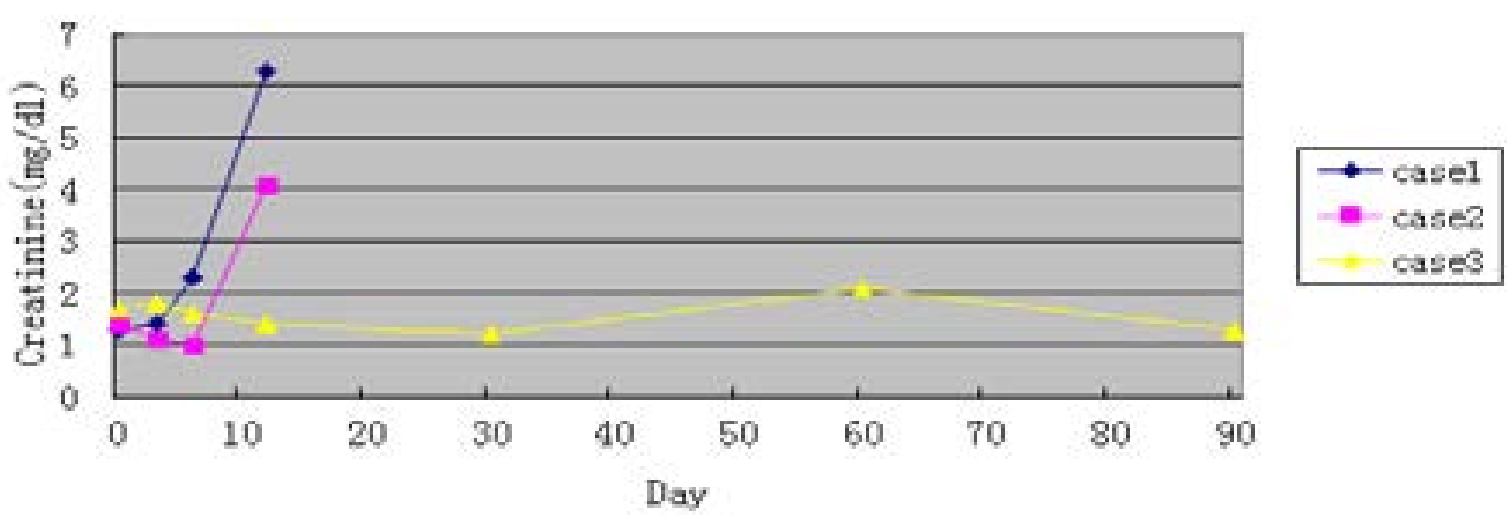

Figure 4: Serum creatinine levels during hospitalization. Serum creatinine levels peaked on day 12 for case $1(6.3 \mathrm{mg} / \mathrm{dl})$ and case 2 $(4.1 \mathrm{mg} / \mathrm{dl})$, on day 60 in case $3(2.1 \mathrm{mg} / \mathrm{dl})$.

On the 10th day of hospitalization, grade IV hepatic encephalopathy developed rapidly in cases 1 and 2, where serum ammonia levels were 84 and $165 \mathrm{~mol} / \mathrm{l}$, respectively. Lactulose was administered to both the cases. Liver support with molecular adsorbents recirculating system was started in case 1 . Between day 10 and 11, a total of two sessions (8 hours each) of molecular adsorbents recirculating system treatment were given. However, case 1 remained unconscious. On the $12^{\text {th }}$ day, both case 1 and 2 failed to maintain blood pressure and consequently passed away. Case 3 was transferred to a hospital in Hong Kong to continue treatment after 3 months of hospitalization in Guangzhou but died of liver failure 2 months later.

African Health Sciences Vol 16 Issue 4, December, 2016

\section{Discussion}

Kidney transplantation is considered to be the best longterm treatment for end-stage renal failure. However, HBV infection constitutes a major problem since it is common in allograft recipients and is a significant cause of morbidity and mortality after transplantation ${ }^{11}$. Lamivudine is a NA recommended for prophylaxis against HBV reactivation in patients with chronic HBV infection who undergo kidney transplantation under immune suppression. Fabrizi and colleagues ${ }^{12}$ published a meta-analysis inclusive of 14 clinical trials (184 HBV infected kidney recipients); the mean overall estimate for HBV DNA and $\mathrm{HBeAg}$ clearance and ALT normalization were 91\%, 27\%, and 
$81 \%$, respectively. When HBV replication was suppressed in a sustained manner, the accompanying reduction in histological activity of chronic HBV infection decreased the risk of cirrhosis and hepatocellular carcinoma ${ }^{13}$.

However, there are no standard guidelines for the duration of prophylactic therapy because lamivudine cannot completely eradicate HBV. HBV persists as covalently closed circular DNA that serves as a template for gene transcription, possibly for decades, in the nucleus of infected hepatocytes ${ }^{14}$. Once antiviral treatment is started, the duration is usually indefinite. However, from a clinician's point of view, a drug should not be used for a lifelong period unless there is no other alternative 9 . Chan and colleagues ${ }^{15}$ reported that discontinuation of lamivudine was attempted in 12 low-risk HBsAg-positive kidney recipients after stabilization, and was successful in $5(41.7 \%)$, whereas 7 patients $(58.3 \%)$ required retreatment due to resurgence of HBV DNA levels. Huang and colleagues ${ }^{16}$ observed that the liver-related mortality rate was not significantly higher in HBsAg-positive kidney or heart recipients who discontinued lamivudine treatment compared with continuously treated recipients.But the current study indicates that $\mathrm{HBV}$ reactivation after lamivudine withdrawal can be associated with severe consequences. When HBV reactivates, viral loads are high and trigger an immune response. Immune restoration can lead to rapid clearance of infected hepatocytes with spontaneous arrest of viral multiplication ${ }^{11}$. Biochemical dysfunction may develop following resurgence of $\mathrm{HBV}$ viremia and result in acute liver failure.

Immuno suppression may augment $\mathrm{HBV}$ replication by diminishing activity of cytotoxic T-lymphocytes and HBV DNA contains a glucocorticoid-responsive element that enhances HBV replication ${ }^{17}$. The immunocompromised status exacerbated withdrawal hepatitis. Lamivudine therapy must continue as long as the immunosuppressive therapy lasts.

In this study, two patients had sero-reversion from $\mathrm{HBe}-$ $\mathrm{Ab}$ to $\mathrm{HBeAg}$ which is a surrogate marker of HBV replication. Immediate antiviral treatment with lamivudine was undertaken to rescue these patients with advanced liver disease. The patients failed to get any clinical benefit from the re-administration of lamivudine despite a rapid viral suppression. The TB and INR values accurately predict the severity of necroinflammation, which were increased in these patients. Renal dysfunction developed in all patients and was multifactorial. All three cases rapidly evolved from hepatitis flares to acute liver failure and death. Due to the high mortality rate, patients with rapid progression to liver failure should be evaluated for liver or combined liver-kidney transplantation ${ }^{18}$.

This report has some limitations including the retrospective approach, recruitment bias and the fact that it is a small case-series. Furthermore, there is a lack of data on HBV genotypes and liver pathology during the flares. Nevertheless, the data suggests several recommendations. In addition to laboratory testing for HBV, kidney transplant recipients should also be evaluated for a history of HBV infection and make sure to prescribe NA. In case of resistance to NAs, an appropriate rescue therapy should be added or switched to another more effective NA.

\section{References}

1. Liaw YF, Chu CM. Hepatitis B virus infection. Lancet. [Research Support, Non-U.S. Gov't]. 2009 Feb 14;373(9663):582-92.

2. Liang X, Bi S, Yang W, Wang L, Cui G, Cui F, et al. Epidemiological serosurvey of hepatitis B in China--declining HBV prevalence due to hepatitis $B$ vaccination. Vaccine. [Research Support, Non-U.S. Gov't]. 2009 Nov 5;27(47):6550-7.

3. Kalia H, Fabrizi F, Martin P. Hepatitis B virus and renal transplantation. Transplant Rev (Orlando). [Review]. 2011 Jul; 25(3):102-9.

4. Chan TM, Chapman J, Lee CJ, Morad Z, Ona ET, Park $K$, et al. A survey on the prevalence and management of hepatitis B after renal transplantation in Asian-Pacific countries. Transplant Proc. [Multicenter Study]. 2004 Sep;36(7):2126-7.

5. Cosconea S, Fontaine H, Meritet JF, Corouge M, Sogni P, Vallet-Pichard A, et al. Benefits associated with antiviral treatment in kidney allograft recipients with chronic hepatitis B virus infection. J Hepatol. 2012 Jul;57(1):55-60. 6. Papatheodoridis GV, Dimou E, Papadimitropoulos V. Nucleoside analogues for chronic hepatitis B: antiviral efficacy and viral resistance. Am J Gastroenterol. [Review]. 2002 Jul;97(7):1618-28.

7. Kidney Disease: Improving Global Outcomes (KDIGO) Transplant Work Group. KDIGO clinical practice guideline for the care of kidney transplant recipients. $\mathrm{Am}$ J Transplant. 2009;9(Suppl 3):S1-S157.

8. Chien RN, Liaw YF. Nucleos(t)ide analogues for hep- 
atitis B virus: strategies for long-term success. Best Pract Res Clin Gastroenterol. [Research Support, Non-U.S. Gov't Review]. 2008;22(6):1081-92.

9. Yeh CT, Hsu CW, Chen YC, Liaw YF. Withdrawal of lamivudine in $\mathrm{HBeAg}$-positive chronic hepatitis $\mathrm{B}$ patients after achieving effective maintained virological suppression. J Clin Virol. [Research Support, Non-U.S. Gov't]. 2009 Jun;45(2):114-8.

10. Larson AM. Diagnosis and management of acute liver failure. Curr Opin Gastroenterol. [Review]. 2010 May;26(3):214-21.

11. Vallet-Pichard A, Fontaine H, Mallet V, Pol S. Viral hepatitis in solid organ transplantation other than liver. $J$ Hepatol. [Review]. 2011 Aug;55(2):474-82.

12. Fabrizi F, Dulai G, Dixit V, Bunnapradist S, Martin P. Lamivudine for the treatment of hepatitis B virus-related liver disease after renal transplantation: meta-analysis of clinical trials. Transplantation. [Meta-Analysis]. 2004 Mar 27;77(6):859-64.

13. EASL clinical practice guidelines: Management of chronic hepatitis B virusinfection. J Hepatol. [Practice Guideline]. 2012 Jul;57(1):167-85.

14. Yang HC, Kao JH. Persistence of hepatitis B virus covalently closed circular DNA in hepatocytes: molecular mechanisms and clinical significance. Emerg Microbes Infect. [Review]. 2014 Sep;3(9):e64.

15. Chan TM, Fang GX, Tang CS, Cheng IK, Lai KN, Ho SK. Preemptive lamivudine therapy based on HBV DNA level in HBsAg-positive kidney allograft recipients. Hepatology. [Clinical Trial Research Support, Non-U.S. Gov't]. 2002 Nov;36(5):1246-52.

16. Huang YW, Liu CJ, Lai MY, Lee PH, Tsai MK, Wang SS, et al. Discontinuation of lamivudine treatment for hepatitis flare after kidney or heart transplantation in hepatitis B surface antigen-positive patients: A retrospective case series. Clin Ther. [Research Support, Non-U.S. Gov't]. 2006 Sep;28(9):1327-34.

17. Tur-Kaspa R, Burk RD, Shaul Y, Shafritz DA. Hepatitis $\mathrm{B}$ virus DNA contains a glucocorticoid-responsive element. Proc Natl Acad Sci U S A. [Research Support, Non-U.S. Gov't Research Support, U.S. Gov't, Non-P.H.S. Research Support, U.S. Gov't, P.H.S.]. 1986 Mar; 83(6):1627-31.

18. Tsai SH, Chang HM, Hsieh CB, Chao YC, Hsieh TY. Acute fulminant hepatitis $\mathrm{B}$ in a patient with diabetic nephropathy treated successfully with concomitant lamivudine and molecular adsorbents recirculating system. $J$ Infect. [Case Reports]. 2006 Jul;53(1):e19-23. 